\title{
Significado que le dan los voceros y las voceras del consejo comunal "PRAYVAR" a la participación ciudadana y su relación con el desarrollo humano
}

\author{
Elvia Lucia Jurado Velez ${ }^{1}$
}

1 UNAN-Managua, FAREM-Estelí. Attitudes Based Learning Cooperative. MSc in Management of Community Development. E-mail: elvia1709@hotmail.com.

\section{RESUMEN}

Este artículo muestra la primera etapa de preparación de la ejecución de la investigación acerca del significado que le dan los voceros y las voceras del Consejo Comunal "PRAYVAR" a la participación ciudadana y su relación con el desarrollo humano. El artículo se organiza en 3 secciones. La primera, presenta los aspectos generales de la investigación. La segunda el referente teórico conceptual recolectado para sustentar la investigación, y por último, el referente metodológico.

En esta investigación se hizo uso de la metodología cualitativa y el método etnográfico. La muestra está representada por voceros y voceras del consejo comunal y personas de la comunidad. Para culminar la investigación se está haciendo uso de técnicas de recolección de datos con la observación participante, la entrevista a profundidad y la semiestructurada. Posteriormente se realizará el análisis e interpretación de la información con categorías en el programa Weft QDA y finalmente se llegarán a las conclusiones finales. Se espera que en ellas se logre concretar lo que los voceros y las voceras interpretan como participación ciudadana.

Palabras claves: Participación Ciudadana; Consejo Comunal; Desarrollo Humano. 


\section{Meaning given by the spokespersons of the council and community "PRAYVAR" to the citizen participation and its relation to human development}

Elvia Lucia Jurado Velez ${ }^{1}$

1 National Autonomous University of Nicaragua. Managua. Regional Multidisciplinary Faculty Estelí. Learning Based on Cooperative Attitudes. MSc in Management of Community Development.

\section{ABSTRACT}

This article describes the first step of preparing the implementation of the research about the meaning given by the spokesmen and spokeswomen of Common Council "PRAYVAR" to the citizen participation and its relationship to human development.The article is organized into 3 sections. The first presents the general aspects of the research. The second one shows the conceptual theoretical reference collected to support the research, and finally, the methodological reference.

In this research qualitative methodology was used and the ethnographic method was applied. The sample is represented by spokespersons of the community council and community members. To complete the investigation data collection techniques were used with participant observation, in-depth interviews and semi structured one. Subsequently the analysis and interpretation of the information categories in the Weft QDA program will run and eventually

come to final conclusions. Is expected to achieve them and realize what the spokesmen and spokeswomen interpreted as citizen participation.

Keywords: Citizen Participation; Common Council; Human Development. 


\section{ASPECTOS GENERALES}

La última década ha representado para la República Bolivariana de Venezuela un cambio en la forma de organización social, a través de la implementación de la participación ciudadana en la toma de decisión de la vida pública, como un mecanismo de derecho y deber social, plasmado en la Constitución de la República Bolivariana de Venezuela (1999).

La presencia de participación ciudadana asigna al pueblo venezolano un papel protagónico en la gestión pública al tener la posibilidad y obligación de compartir responsabilidades con el estado a través de la participación. Pedro Ibarra (2001, p. 1) menciona al respecto que "La gente debe organizase para la acción colectiva encaminada a influir en la circunstancia y decisiones que afecten a sus vidas".

Antes de la Constitución de la República Bolivariana de Venezuela del año 1999, las comunidades establecían una forma de organización a través de las Asociaciones de Vecinos que eran agrupaciones de personas que viven en un mismo sector, que se legitiman a fin de responder a sus intereses y problemas de la comunidad. Ellas gestionan con las figuras del gobierno local, tales como alcaldías, Consejo Municipal, Jefatura, etc. presentando planteamientos y cooperando con estos organismos para mejorar y solventar sus demandas comunitarias. Esta figura de asociación de vecinos cambia con la promulgación de la Ley Orgánica de los Consejos Comunales en el año 2006 y modificada en el año 2009.

El objetivo de los Consejos Comunales está determinado en la Ley Orgánica de los Consejos Comunales (2009, p. 1) en su artículo No. 2 de la siguiente forma:

... Son instancias de participación, articulación e integración entre los ciudadanos, ciudadanas y las diversas organizaciones comunitarias, movimientos sociales y populares, que permiten al pueblo organizado ejercer el gobierno comunitario y la gestión directa de las políticas públicas y proyectos orientados a responder a las necesidades, potencialidades y aspiraciones de las comunidades, en la construcción del nuevo modelo de Sociedad Socialista de igualdad, equidad y justicia social.

Estos ámbitos han sido asumidos con muchas responsabilidades por grupos de la sociedad civil y conocer estas experiencias resulta de suma importancia como mecanismo para apoyar y promocionar la participación ciudadana para mejorar la calidad de vida de las comunidades en la búsqueda del Desarrollo Humano. La participación representa la máxima expresión de ese Desarrollo Humano, ya que posibilita las capacidades de los seres humanos para la solución de sus propios problemas.

\section{REFERENTE TEÓRICO}

Para SINERGIA (2000, p. 35) la participación constituye un acto que realizan las personas cuando se encuentran en un espacio social, de carácter público y de naturaleza política. Es una forma de ejercer la voluntad con un fin predeterminado que es posible conseguirlo con el intercambio de varias personas.

A través de la participación es posible expresar nuestras ideas, pensamientos, intereses, intenciones, opciones y modos de ver la vida, afirmándonos como sujetos soberanos, es decir se hace posible el ejercicio de la voz y la expresión, la voluntad y la capacidad para construir realidades con los otros.

El término de participación es asociado con organizaciones de la sociedad civil, organizaciones cooperativas, comunidades de autoayuda, organizaciones sindicales, movimientos sociales, emisión de voto, asistencia comunitaria que emergen 
de la sociedad para gestionar la práctica social. Es así como podemos observar en la sociedad, comunidades participando de diferentes formas: con intereses específicos relacionados con sectores particulares (mujeres, niños, jóvenes, etc., en defensa de temas públicos (educación, salud, vivienda, ambiente, derechos humanos, entre otros), agrupaciones con intereses económicos (cooperativas y sindicatos), proyectos de autogestión (abasto popular, comedores, etc.).

Es posible distinguir varios tipos de participación. Al respecto Ziccardi (2001, p. 302) nos presenta la siguiente clasificación:

- Participación social: agrupación de individuos para alcanzar objetivos predeterminados.

- Participación comunitaria: determinada por actividades de tipo asistencialista que no requieren interacción con el estado.

- Participación ciudadana: relación entre ciudadanos y estado interviniendo en las actividades públicas para hacer valer sus intereses sociales.

La participación orientada hacia la gestión y toma de decisión pública es un proceso cuyos protagonistas son el gobierno y la sociedad. Estos espacios de apertura se han dado en diferentes niveles, especialmente el local. $Y$ es aquí donde se ubica la participación ciudadana. Bolos (2003, p. 39) nos dice al respecto: “..., representan una respuesta -individual o colectivadesde lo social a una convocatoria realizada por parte de las autoridades gubernamentales en aquellos espacios institucionales que estas designan o crean para involucrar a sectores de la población en alguna actividad específica".

Es así como la participación ciudadana representa el proceso mediante el cual la sociedad organizada responde al requerimiento del estado para involucrarse en la gestión pública, a través de acciones concretas que el gobierno delega o que las propias circunstancias le imponen.
Para Cunill citada por Oropeza (2005, p. 212)

La participación puede construir un medio de reconocimiento y expresión de los intereses socialesmarginados. Especialmente, si se entiende que la participación ciudadana es ante todo, un conjunto de instrumentos y procedimientos que las instituciones democráticas ponen a disposición de los grupos sociales más desfavorecidos para facilitar su intervención en la vida política y para estimular su desarrollo colectivo.

Para ello deben existir dos condicionamientos: en primer lugar, un Estado que propicie las oportunidades de que dichas comunidades gestionen en la administración pública ya sea en el ámbito de formulación de esas políticas como en la planificación ejecución y evaluación, y en segundo lugar, unas comunidades comunicativas, organizadas y dispuestas a comprometerse y asumir corresponsabilidad con ese Estado.

Con la implementación de los Consejos Comunales se logra una forma de integrar el Estado y la sociedad, delegando en el pueblo una responsabilidad. En este escenario, as comunidades organizadas tienen el deber y derecho de afrontar sus asuntos.

Según López (2011, p. 37) los Consejos Comunales son:

una instancia directa de acción ygestión de políticas públicas y proyectos que tienen los ciudadanos para solucionar y mejorar sus condiciones de vida a través de un cogobierno en áreas tales como: salud, educación, infraestructura, deporte, comunicaciones, servicios públicos, defensa territorial, economía solidaria, entre otros.

Los principios que rigen los consejos comunales están detallados en la Ley Orgánica de los Consejos Comunales (Op cit, p. 1): 
participación, corresponsabilidad, democracia, identidad nacional, libre debate de las ideas, celeridad, coordinación, cooperación, solidaridad, transparencia, rendición de cuentas, honestidad, bien común, humanismo, territorialidad, colectivismo, eficacia, eficiencia, ética, responsabilidad social, control social, libertad, equidad, justicia, trabajo voluntario, igualdad social y de género.

Dentro de las definiciones de términos me parece propicio traer a colación el de vocero y vocera: “...es la persona electa mediante proceso de elección popular, a fin de coordinar el funcionamiento del consejo comunal, la instrumentación de las decisiones de la Asamblea de Ciudadanos y Ciudadanas" (Ididem).

Los voceros son las personas electas por la asamblea de ciudadanos y ciudadanas y tienen la responsabilidad de conducir cada una de las unidades de trabajo y sus decisiones están subordinadas a dicha asamblea. Pues según el artículo No. 19 (Op cit, p. 9)

La asamblea de ciudadanos y ciudadanas es la máxima instancia de deliberación y decisión para el ejercicio del poder comunitario, la participación y el protagonismo popular, sus decisiones son de carácter vinculante para el consejo comunal en el marco de esta Ley.

El consejo comunal según la Ley Orgánica de Los Consejos Comunales, artículo 19 (Ibídem). "Está estructurado según su funcionamiento de las siguientes instancias: la asamblea de ciudadanos y ciudadanas; el colectivo de coordinación comunitaria; la unidad ejecutiva; la unidad administrativa y financiera comunitaria; y la unidad de contraloría social".

Con ese recorrido por la Ley de los Consejos Comunales se puede constatar una modalidad participativa que permiten a las comunidades ejercer directamente la gestión pública a fin de contribuir con el estado para satisfacer las necesidades y expectativas de los ciudadanos.

El sistema político democrático se ve fortalecido cuando sus ciudadanos deciden sobre los asuntos públicos. Cuando los habitantes del país se comprometen y responsabilizan por atender asuntos que le son propios en la vida social y política. De esta forma tendremos una sociedad cohesionada y apoyada en sus instituciones y sus ciudadanos.

Es así como la participación se hace necesaria e indispensable en un sistema democrático donde los ciudadanos tienen el derecho y el deber de integrarse la gestión y decisiones de su entorno social.

Según Hernández (Ibídem, p. 247) la democracia conlleva a la participación y responsabilidad de sus ciudadanos a comprometerse con la gestión. "porque el derecho a la participación es de todos, todos asumen el deber de dar cuenta de su uso"

Para Ziccardi, citado por Mellado (Op cit, p. 20)

La participación cotidiana del ciudadano en decisiones y ejecución de las mismas que atañen a su vida cotidiana es la democracia participativa. Por esta razón, la participación es un componente central de la democracia, puesto que si bien suele considerarse que el primer escalón de la misma es el voto, en tanto derecho universal de los ciudadanos a elegir a sus representantes, la participación agrega a esta forma de gobierno su capacidad de ser gobierno de todos los ciudadanos.

El papel de todo gobierno debe ser propiciar espacios adecuados permitiendo la toma de decisión y ejecución de proyectos para elevar las condiciones de vida de sus ciudadanos, haciendo efectivo el derecho a la participación y democratizando el poder hacia el logro del desarrollo humano. 
El desarrollo humano ha sido ampliamente trabajado, socializado y divulgado por el Programa de las Naciones Unidas para el Desarrollo (PNUD) quien lo define de la siguiente forma en el Informe de Desarrollo Humano 1990 (s/f, p. única):

EI PNUD define el Desarrollo Humano en su informe de 1990 como

El proceso en el que se amplían las oportunidades del ser humano. En principio, estas oportunidades pueden ser infinitas y cambiar con el tiempo. Sin embargo, a todos los niveles del desarrollo, las tres más esenciales son: disfrutar de una vida prolongada y saludable, adquirir conocimientos $y$ tener acceso a los recursos necesarios para lograr un nivel de vida decente.

Mirar una realidad determinada desde el paradigma del desarrollo humano implica superar la medición mediante categoría cuántica de lo que tenemos y poseemos. Es determinar las condiciones (sociales, económicas, políticas, culturales, entre otros), más allá de la acumulación y trascender a escenarios más complejos y dinámicos como al acceso a la salud, la educación y el respeto de sus derechos fundamentales.

Al respecto Chávez, (2006, p. 123) nos dice que el concepto de desarrollo humano surge como una respuesta con el énfasis desproporcionado que históricamente se ha brindado a variables puramente económicas (como el PIB per cápita) para analizar el desarrollo de un país, región, o individuo; se basa en el universalismo, es decir, en el reconocimiento de las reivindicaciones vitales, en el cual se pueda ofrecer y garantizar, al mismo tiempo, la posibilidad de que todas las personas aumenten su capacidad de forma íntegra y que puedan darle a estas capacidades el mejor uso posible.
Desde esta perspectiva el desarrollo no se mide por cuanto tiene o produce un país, sino como se encuentra y como vive su población. Y determinar este segundo aspecto, pasa por establecer cuánto está preparado una sociedad para asumir su realidad y la capacidad de transformarla, es decir la disposición, compromiso y responsabilidad para aplicar procesos de participación, que según el sistema político venezolano declarado como democrático en la Constitución de la República Bolivariana de Venezuela le faculta con la participación ciudadana.

A manera de síntesis, podría decir que estar inmerso en su sistema democrático implica tomar conciencia en cuanto a la responsabilidad que se tiene con su destino y el de los suyos, y es la participación ciudadana el mecanismo para hacerlo efectivo, que en definitiva es como se alcanzará el Desarrollo Humano.

\section{REFERENTE METODOLÓGICO}

El método a utilizar en este estudio es el cualitativo que para Cook y Reichardt (2005, p. 28) "postula una concepción global fenomenológica, inductiva estructuralista, subjetiva, orientada al proceso y propia de la antropología social".

Este método según Ruiz (2012, p. 17), permite conocer la realidad desde adentro, a fin de captar el significado particular que cada participante le atribuye al rol que desempeña como protagonista. De esta forma será posible captar esta realidad de la vida social como desde la visión de los propios voceros/as del consejo comunal "PRAYVAR". Los fenómenos sociales que se dan en este contexto comunitario pueden ser presentados mediante la construcción explicativa e interpretativa de los propios involucrados.

Dentro del método cualitativo es posible distinguir varios tipos según la estructura de la naturaleza que se va a estudiar. 
Martínez (s/f, p. única) clasifica los siguientes: hermenéutico-dialéctico, fenomenológico, etnográfico, investigación-acción, historias de vida.

Al respecto de esta investigación se asume el método etnográfico, que según Malinowski, citado por Martínez (Op cit, p. 2) es:

...aquella rama de la antropología que estudia descriptivamente las culturas. Etimológicamente, el término etnografía significa la descripción (grafé) del estilo de vida de un grupo de personas habituadas a vivir juntas (ethnos). Por tanto, el ethnos, que sería la unidad de análisis para el investigador, no solo podría ser una nación, un grupo lingüístico, una región o una comunidad, sino también cualquier grupo humano que constituya una entidad cuyas relaciones estén reguladas por la costumbre o por ciertos derechos y obligaciones recíprocos.

Con este método es posible entrar a conocer un grupo social que se desarrolla con una forma y estilo particular, producto de las relaciones que establecen sus integrantes. Los conceptos de las realidades estudiadas vienen dados por las normas, reglas, estilos, modos de vida que adoptan sus actores. El estudio de este grupo debe ser realizado de una forma holística, es decir, analizando el todo y todas sus partes, donde cada cosa se relaciona con las demás para adquiere un significado propio, tanto global como en lo particular. Se trata entonces de recoger datos del grupo de voceros/as del consejo comunal mencionados y construir significados de su realidad a partir de sus expresiones habladas y escritas, y la conducta observable.

La muestra de la investigación es intencionada y razonada, que según Vásquez y otros (2006, p. 43), se elige con criterios de representatividad y significación. Es decir se eligen a las personas que tengan más posibilidades de responder a las preguntas que me planteo en la investigación. Igualmente es acumulativa y secuencial. La información es recolectada con la muestra hasta saturar la información. $Y$ finalmente es flexible y reflexiva. La muestra inicial puede llegar a requerir de la incorporación de otros informantes hasta que se logren el objetivo general.

Esta representatividad a la cual hago referencia no se refiere a la representatividad probabilística sino intencionada y razonada, es decir con un objetivo predeterminado y lógicamente estructurado en concordancia con los objetivos de esta investigación. Es así como que al asumir la opción ontológica donde la realidad es estructural y sistémica, y siguiendo las recomendaciones de los autores y las autoras antes mencionadas, la muestra es reducida a una amplitud numérica de casos, en esta investigación serán los voceros y las voceras del consejo comunal "PRAYVAR", cuya escogencia depende de la relevancia en los objetivos de esta investigación, donde se considera el rol que asume cada vocero/a dentro del consejo comunal, el sexo y la edad. El número de personas a entrevistar dentro del consejo comunal depende de la medida en que ellos aportan información importante, relevante y profunda para lograr la investigación.

En cuanto al informante clave, Canales (2006, p. 249) nos dice que un informante clave debe tener las siguientes características: conocer la realidad que se pretende investigar; ser una persona respetada por las demás personas involucradas y con quien se puede tener una relación de confianza y conocimiento del contexto. También recomienda a diferencia de la autora anterior que no sea un número muy reducido. Ellos son la resultante de un proceso de investigación a través de la interacción y el intercambio, por lo cual no están predeterminados sino que se van construyendo a lo largo de la investigación.

Los instrumentos, procedimientos, estrategias y técnicas utilizadas deben estar acorde al método escogido (etnográfico), por lo cual se recurre a la 
observación participante, la entrevista a profundidad y la entrevista semi-estructurada.

Los instrumentos a utilizar serán la guía de observación y el guion de entrevista.

Para el análisis de la información se definen unas precategorías que luego son confirmadas y modificadas según sea el caso, en función de la información suministrada por los informantes claves. Las mismas son construidas con apoyo del referente metodológico plasmado en el capítulo II.

Las categorías para Galeano (2004, p. 41) son conceptos que van dotando de contenido a la investigación según el área de investigación relacionada con las preguntas de investigación. Las categorías son construidas a partir de la observación e información recabada.

Posteriormente serán sometidos a la unidad de análisis de significados. Según Albert (2006, p. 180) "son categorías lingüísticas que usan los actores humanos para referirse a la vida social, como definiciones, ideologías, o estereotipos", ya que mi investigación se centra en describir ese significado que atribuyen los voceros y las voceras del consejo comunal "PRAYVAR" al rol que desempeñan como expresión de la participación ciudadana como un deber y un derecho social, y su relación con el desarrollo humano.

Los datos serán administrados a través de un programa denominado Weft QDA que según Martínez, (s/f, p. 3)

Es una herramienta que permite trabajar con diferentes tipos de datos en forma de texto como entrevistas, documentos y notas de campo ..... permite marcar y agrupar diferentes segmentos del trabajo escrito según categorías predeterminadas para poder clasificar la información y facilitar su posterior análisis.
A partir de la categorización se creará una teoría propia y particular que da explicación al significado de la participación ciudadana de los voceros y las voceras en el consejo comunal "PRAYVAR" según el rol que desempeñan, en relación al desarrollo humano. Se logra elaborar una imagen representativa de esta realidad. Un contenido lógico y coherente que dé cuenta de este contexto en particular.

Según Ruiz (Op cit, p. 57) B. Glaser y A. Strauss denominaron a este procedimiento la teoría fundamentada que consiste en elaborar una teoría a partir datos. Los conceptos e hipótesis son construidos sistemáticamente durante todo el tiempo de la investigación. La teoría plasmada en la investigación servirá para contrastación los resultados de la investigación.

\section{BIBLIOGRAFÍA}

Albert G., M. J. (2006). La investigación Educativa. España: Mc Graw Hill.

Asamblea Nacional Constituyente. (1999). Constitución de la República Bolivariana de Venezuela. Gaceta Oficial Extraordinaria $N^{\circ}$ 36.860 de fecha 30 de diciembre de 1.999. Año $189^{\circ}$ de la Independencia y $140^{\circ}$ de la Federación. Caracas.

Asamblea Nacional de Venezuela. (2009). Ley Orgánica de los Consejos Comunales. 26 de noviembre de 2009 . Años $199^{\circ}$ de la Independencia y $150^{\circ}$ de la Federación. Caracas

Bolos, S. (2003). Organizaciones Sociales y Gobiernos Municipales. México: Universidad Iberoamericana. Biblioteca Francisco Xavier Clavigero.

Canales, M. (2006). Metodologías de la investigación social. Colección Ciencias Humanas. (1ra edición). Chile: Lom ediciones.

Cook, T., y Reichardt, CH. (2005). Métodos cualitativos y cuantitativos en investigación evaluativa. Pedagogía. (5ta edición). España: Morata. 
Chávez, D y Goldfrank, B. (2004). La izquierda en la ciudad. Participación en los gobiernos locales en América Latina. España: Icaria.

Galeano, M. (2004). Diseño de proyectos en la investigación científica. Colombia: Fondo editorial Universidad EAFIT.

Hernández, L. ( 2006 ). Una mirada sobre Venezuela. Reflexiones para construir una visión compartida. Venezuela: Centro Gumilla. UCAB.

Ibarra, P. y Unceta, K. (2001). Ensayos sobre desarrollo humano. España: Icaria.

López, M. (2011). Democracia participativa en Venezuela (1999-2010). Orígenes, leyes, percepciones y desafíos. Temas de formación sociopolítica. No. 50. Año 2011. Venezuela: Centro Gumilla. UCAB.

Martínez, M. (s/f) Weft-QDA Manual del usuario en español. Versión 1.0. Mimeo. s/n.

Martínez, M. (s/f). Cómo hacer un buen proyecto de tesis con la metodología cualitativa. Recuperado el : 09 de agosto del 2013 de http://prof.usb.ve/ miguelm/proyectotesis.html.

Mellado H., R. (2001). Participación Ciudadana Institucionalizada y Gobernabilidad en la ciudad de México. México: Plaza y Valdés.

Oropeza, A. (2005). La evaluación de la función pública en México. México: Plaza y Valdés.

Programa de Naciones Unidas para el Desarrollo (PNUD). Recuperado el 11 de septiembre del 2013 de http://www.pnud.org.ve/content/view/15/103/.

Ruiz, J. (2012). Metodología de la investigación cualitativa. Serie Ciencias Sociales, vol. 15. (5ta edición). Deusto.

SINERGIA (Asociación Nacional de Organizaciones de la Sociedad Civil. (2000). Informe sobre las garantías y el ejercicio de los derechos de la participación y asociación en Venezuela 20062007. Venezuela: SINERGIA.

Vásquez, M. y otros. (2006). Introducción a las técnicas cualitativas de investigación aplicadas a la salud. España: Grupo GRAAL 5.
Ziccardi, A. (2001). Gobernabilidad de las grandes ciudades en América Latina. Camou, A. Los desafíos de la gobernabilidad. Estudio preliminar y compilación. México: Plaza y Valdés. 